\title{
CAPITAL, CRISE E PRODUÇÃO DO ESPAÇO: AS DETERMINAÇÕES CRÍTICAS DA CONSTRUÇÃO HABITACIONAL EM SÃO PAULO
}

\author{
Luccas Ribeiro do Couto ${ }^{1}$
}

Resumo: A diversidade de interpretações acerca da recente crise mundial capitalista obscureceu por muitas vezes o nexo entre crise, capital e produção social do espaço. Temos a intenção de recuperar tais conceitos em sua condição concreta indissociável, para tanto, propomos investigar as profundas transformações na produção propriamente dita da mercadoria habitação na cidade de São Paulo, no decorrer da década dos anos 2000 período marcado pelo grande aporte de recursos ao setor-, em sua intrincada relação com as novas formas de capitalização, financiamento e crédito. Seria esta fração da produção social uma saída para o capital financeiro em busca de valorização, o que sanearia as crises? Concebe-se que a crise da reprodução do capital tem determinado estas novas configurações - da produção e do financiamento -, que atingem o plano da vida impondo renovadas formas de dominação e acirrando os fetiches. Pretendemos, com isso, desvelar o discurso de modernização na construção civil a ocultar novos e velhos métodos de exploração do trabalho, assim como as peias que agem no cotidiano de quem adquire "o sonho da casa própria".

Palavras-chave: Produção do Espaço; Crise do Capital; Setor Imobiliário; Financeirização.

\section{CAPITAL, CRISIS AND SOCIAL PRODUCTION OF SPACE: THECRITICALDETERMINATIONSOF SÃO PAULO BUILDINGHOUSING}

Abstract: The diversity of interpretations of the recent global capitalist crisis of ten obscured the link among crisis capital and social production of space. Weint end to recorver these concepts in their indussoluble concrete condition, therefore, propose to investigate the deep transformations in the actual production of goods habitations in the city of São Paulo, during the decade of the 2000 - period market by substantial resorces to sector - in its intricater elation ship withthe new forms of capitalization, financing and credit. Was this fraction of social production an outlet for financial capital in search of valoration, what would end crisis? It is conceived that the crisis of there production of capital has given these new configuration - from production and finance - reaching the imposing plan of life, renewed forms of domination and inciting fetishes. Weint end, there fore, to reveal the discourse of modernization in civil construction hide the old and new methods of exploitation of labor, as well as the ties that ac to never $y$ day purchases the dream of own house?

1. Doutorando do Programa de Pós Graduação em Geografia Humana na USP (luccas_usp@yahoo.com.br). 
Key words: Production of Space; Crisis of the Capital; Real State Sector; Financialization.

\section{INTRODUÇÃO}

Antes do problema a que se pretende chegar e seus desdobramentos na Geografia, primeiramente, traz-se à discussão o fenômeno cuja abrangência e efeito sobrelevou-se à cabeça daqueles que enterraram a memória de que o capitalismo não é a força civilizatória harmônica e benevolente com as necessidades sociais; a reprodução destrutiva do capital prova que a sua astúcia tende a pregar peças nos sujeitos que acreditam controlá-lo. A crise nos Estados Unidos permite entrever as categorias e os nexos que se procura discutir, portanto, são presentes igualmente e de forma particular no capitalismo brasileiro. 0 fatídico ano de 2008 para a economia norte-americana trouxe à tona, até aos olhos dos investidores mais incautos, o hiato existente entre a multiplicação de ativos derivados de créditos atrelados a outras apostas futuras e a chamada economia real. Antes desta completa cisão, o setor imobiliário e as operações financeiras pareciam solucionar o problema dos capitais ociosos mundiais e nacionais em busca de valorização, quando a bolha irrompeu². A crise dos EUA foi eloquente: o dinheiro gerado exponencialmente no âmbito financeiro se autonomizou da real valorização do capital no setor imobiliário e na economia de um modo geral, que se tornaram consequências das manipulações financeiras ${ }^{3}$, ou seja, a produção e a circulação de mercadorias dependem progressivamente de transações que canalizem recursos do sistema financeiro para financiamento, investimento e crédito. 0 sumiço deste dinheiro, aparentemente independente, explicitou tal fato, pois não faltaram relatos e análises das sucessivas bancarrotas, fusões ou do socorro a grandes bancos e

2. No caso, o limite desta desproporção se fez efetivo pela incapacidade de pagamento dos consumidores subprimesestadunidenses, dependentes da circulação do capital nas esferas da produção, circulação e seus serviços adjacentes. Isso porque, segundo Alfredo (2010, p. 52), o crédito, como promessa futura de trabalho de quem empresta, está acima da capacidade de pagamento de uma sociedade que prescinde cada vez mais do trabalho, dado o nível de desenvolvimento das forças produtivas atingidos. $\mathrm{O}$ autor demonstra numericamente que de 1964 à 2008, a produção industrial cresceu incessantemente enquanto a força de trabalho manteve-se estável, ou seja, incorporou-se tecnologias que passaram a substituir trabalhadores por processos e máquinas mais eficientes (p. 47-8). Para um esclarecimento mais pormenorizado quanto ao processo de securitização e requalificação dos ativos subprimes, minorando os riscos e possibilitando maiores níveis de alavancagem aos bancos, ver Borça Junior et alli (2008).

3. Esse é o ápice de um movimento analisado por Lênin (1986) na fase imperialista do capitalismo. Nesse período, diz ele, os bancos passaram a controlar a atividade produtiva, cada vez mais inseparável destas instituições que já sugavam boa parte da riqueza socialmente produzida. 
outras instituições que levaram, por conseguinte, à contração do comércio internacional, dos orçamentos públicos e da atividade produtiva. No ápice da crise financeira, diz Harvey (2011, p.13), o mundo foi arrastado para a recessão com a redução da liquidez mundial e a escassez de capital monetário para financiar a circulação do capital. "Na primavera de 2009, o Fundo Monetário Internacional estimava que mais de 50 trilhões de dólares em valores de ativos (quase o mesmo valor da produção total de um ano de bens e serviços no mundo) haviam sido destruídos".

A generalização de um "comportamento" autodestrutivo ${ }^{4}$ põe em questão não só o otimismo de quem ganhava somas avultantes de dinheiro, senão que alerta para o fundamento ${ }^{5}$ em comum de um padrão de acumulação monetária determinante da produção de mercadorias na contemporaneidade. De acordo com Braga (1998, p. 196), a manifestação mais aparente deste padrão de riqueza, apontada por ele como financeirização sistêmica - por não envolver apenas segmentos ou setores, mas sim modificar a ação empresarial, pública e mesmo das famílias - está “[...] na crescente e recorrente defasagem, por prazos longos, entre os valores dos papéis representativos da riqueza [...] e os valores dos bens, serviços, e bases técnico-produtivas em que se fundam a reprodução da vida e da sociedade [...]". Paulani (2010), em sua apreciação sobre a dominância financeira no regime de acumulação vigente, com base nos escritos de Chesnais, qualifica a tese da financeirização sob dois aspectos: o quantitativo e o qualitativo. 0 primeiro, pode ser expresso na dominância financeira do processo de reprodução capitalista, como se observa nos dados entre 1980 e 2006, segundo os quais "[...] o PIB mundial cresceu $364 \%$, ou 4,6 vezes, enquanto que a riqueza financeira mundial cresceu, no mesmo período, $1.525 \%$, ou 16,2 vezes $^{6}$ (p. 5)". O crescimento do estoque de ativos financeiros mais rápido

4. O termo autodestrutivo será explicado como negação de si e por si pelo capital. A palavra comportamento, que o antecede no texto, é empregada propositalmente para se referir à ilusão de um sujeito-mercado que apresenta atitudes subjetivadas na consciência cotidiana, como temperamento de "mal-humor" ou "bomhumor", a depender dos índices das bolsas.

5. A contradição capital-trabalho funda a totalidade moderna capitalista. O capital é o poder totalizador e negativo que submete a si todas as condições de sua autovalorização, por isso domina sua fonte de valor, o trabalho, ao mesmo tempo em que o nega. Essa relação fundamental será objeto de maiores reflexões no corpo deste texto.

6. Os dados citados por Paulani não incluem os valores dos derivativos, já que não há consenso sobre quais seriam estes montantes, diz ela. A impossibilidade de mensurar de forma adequada esses títulos subestima em grande medida o atual volume desta chamada riqueza financeira em circulação. 
que o da renda real e da riqueza real, diz ela, é o resultado de uma enorme massa de riqueza em busca de valorização. Embora esse crescimento exponencial salte aos olhos, a prevalência da valorização financeira é mais qualitativa, do que quantitativa, diz Paulani.

O fato de sua exterioridade em relação à produção ter se alojado no seio mesmo da esfera produtiva é que explica um sem número de mudanças ai ocorridas, seja na relação de trabalho [...], seja na forma de gestão do processo de trabalho [...], seja ainda na organização do processo produtivo enquanto tal [...]. Assim, a produção de renda e riqueza real passa a se dar sob a lógica e os imperativos da valorização financeira. Seus processos devem ser adequados às necessidades de giro rápido e pronta condição de aproveitar ganhos que a acumulação financeira impõe, o "mínimo" de rendimento real que a produção deve gerar é muito alto, dada a elevada valorização dos ativos financeiros (o que pressiona no sentido de uma exploração do trabalho ainda mais violenta), a operação do caixa deve ser tal que ele funcione não como atividade de apoio a produção, mas como centro de lucro adicional, os gestores dos grandes grupos de capital devem buscar, antes de tudo, a maximização do valor acionário da empresa, fazendo o que for necessário (fraudando demonstrativos, recomprando suas próprias ações etc.) $(2010$, p. 3).

Portanto, se a possibilidade de fazer dinheiro gerar mais dinheiro penetrou os poros da reprodução social e econômica, a compreensão deste fenômeno não passa pelo clamor moral contra a classe rentista financeira, alcunhada de "parasita" (KURZ, 2003; PRADO, 2013), já que todas as classes tentarão se apropriar da maior quantidade da forma monetária e se livrar da produção de coisas (empresários em geral) ou do próprio trabalho (a poupança, os investimentos diversos das famílias, o roubo, etc.); o dinheiro produzindo mais dinheiro é a forma mais desenvolvida da reprodução capitalista e não o seu contrário (PAULANI, 2011).

Marx, no primeiro livro de O Capital, deixa claro que está na natureza do dinheiro - ou outros papéis representativos da riqueza - se autonomizar e a expõe concretamente no seu livro terceiro, quando analisou a crise financeira do século XIX. Ele observou que os meros títulos de propriedade de ações sobre empresas, ferrovias, minas, etc., - representantes dos capitais existentes -, quando não se acumulam pari passu ao processo real de reprodução, mas elevam seu valor sendo negociados como mercadorias (valores-capitais), criam uma riqueza imaginária quando referidas à parte de valor que originalmente representavam. De onde ele mesmo indagou até que ponto a acumulação de capital monetário propriamente dito (o que vale na atualidade para os diversos "papéis" representantes nominais da riqueza) indica a acumulação real de capital, ou seja, reprodução em escala ampliada (1988, 3 V, p. 
12-13) $)^{7}$ “Ganhar e perder pelas flutuações de preço desses títulos de propriedade [...] tornase virtualmente mais e mais resultado do jogo, que toma o lugar do trabalho, como modo original de adquirir propriedade do capital, e também o lugar da violência direta (grifo nosso, Ibid., 3 V, p. 13)."

Sobre este jogo, Robert Kurz (2002) demonstra que se autonomizou da real produção de valor e tornou-se, agora mais que na época de Marx, uma pletora de riqueza imaginária uma das formas que assume a categoria de capital fictício -, em que pese a "mão visível" do Estado $^{8}$ nas tentativas históricas de harmonizar ou regular a gana do capital. 0 "capitalismo de cassino" assinala Kurz, é o destino altamente lucrativo dos capitais ociosos; por aqui a passagem formal $D-D^{\prime}$ (dinheiro gerando mais dinheiro) suprime o momento do trabalho criador de valor e faz crer que a mera propriedade sobre o capital faz brotar a riqueza. Não obstante, este fetiche é posto à prova nas crises, quando os títulos de propriedade sobre ativos se desvalorizam e têm, em última instância, que corresponder à produção social de valor. A nuvem financeira que se multiplica a si mesma paira sobre o mundo atrás de atividades nas quais esse aumento exponencial de dinheiro - a acumulação monetária possa ser reinvestido e, com isso, restabelecer a unidade contraditória entre esta massa de capitais ociosos e o trabalho produtor de valor. Os presentes acontecimentos demonstraram que a produção e o consumo do setor imobiliário norte-americano não resolveram a necessidade do enorme montante de dinheiro em circulação de açambarcar quantidades cada vez maiores de valor, fenômeno que deixa vislumbrar a contradição do capital que leva à crise e à busca pela riqueza nas esferas financeiras (ALFREDO, 2010; KURZ, 2002; HARVEY, 2011).

\section{CRISE E PRODUÇÃO DO ESPAÇO}

São diversos os campos disciplinares, as correntes de pensamento e os argumentos que demonstram ser o setor imobiliário, apoiado no mercado financeiro, o ramo privilegiado

7. As citações ao longo do texto fazem menção à obra consultada utilizando números arábicos para a referência do Livro e os números romanos para o Tomo, seguido da página citada quando houver.

8. Importante tomar nota do debate em voga de cunho keynesiano, que aponta saídas para a crise e defendem a "mão visível" do Estado em detrimento à "mão invisível" do mercado. Cf. Dossiê da Crise e Dossiê da Crise II (2008; 2010). 
para a solução das crises do capital. No âmbito da própria Geografia o debate é amplo e constantemente reatualizado. Harvey é o geógrafo que recentemente publicou uma série de conferências e livros versando sobre as contradições do capital, inclusive o último, "O Enigma do Capital e as crises do capitalismo" (2011), tratou da crise dos EUA. É possível observar em sua obra um caminho interpretativo no qual recupera a imanência crítica do capital para consigo mesmo, executada fundamentalmente por uma tendência à superacumulação. As crises não seriam resolvidas, constituem sim uma irracionalidade do capital que racionalizaria suas contradições, diz ele, sendo deslocadas sob novas formas de acumulação. Estas envolveriam a (re)produção de um espaço adequado à nova etapa, por isso a geografia histórica do capitalismo ser expressa como uma eterna destruição criativa, por meio da qual a reformulação constante de novos espaços geográficos, através do desenvolvimento geográfico desigual, ajustes espaciais, compressões espaço-temporais ou acumulação por espoliação, permitiriam um renovado potencial de valorização (2005a; 2005b; 2008; 2011; 2012). Em "O enigma do Capital”, Harvey enfatiza que a produção do espaço, ao menos parcialmente, teria uma função estabilizadora; segundo ele, a urbanização da China seria apenas o epicentro de um movimento global de urbanização, impulsionado pela integração dos mercados financeiros, que consumiria os capitais excedentes. Já Smith $(2006,2007)$ utiliza a noção de fronteira - numa analogia com a marcha para oeste nos EUA - para caracterizar a estratégia global do capital de reestruturar os antigos centros de cidades ao redor do mundo em novas frentes de acumulação; a produção de um renovado ambiente construído seria capaz de reverter a queda nas taxas de lucro que atinge o setor industrial. Lefebvre também afirma que o setor imobiliário tem a função essencial de se contrapor à queda nos lucros. De setor subsidiário, secundário, o imobiliário se tornaria o principal em caso de recessão, "A mobilização das riquezas fundiária e imobiliária deve ser compreendida como uma das grandes extensões do capitalismo financeiro, desde um certo número de anos [...]" (200 -, p. 40). O espaço inteiro está inserido na produção de mercadorias, fragmento por fragmento, e enquanto decresce a mais-valia formada e realizada na indústria, “[...] aumenta a parte da mais-valia formada e realizada na especulação e pela construção imobiliária [...] De contingente, torna-se essencial (2004, p. 147)". No Brasil, os muitos estudos de Carlos (2004) sobre o capital financeiro e o setor imobiliário apontam igualmente nessa direção. Ela considera, a partir da cidade de São 
Paulo, entre outras, que a crise no processo produtivo determinou os investimentos do capital-monetário ocioso nos ativos financeiros, os quais se realizam na própria cidade, no setor imobiliário, em detrimento do setor industrial. Portanto, a produção do espaço urbano vem a ser a condição sinequa non para efetivar as exigências da acumulação, articulada ao plano mundial e através de uma nova relação Estado-espaço, a propiciar os quadros normativos e infraestruturais adequados a este novo momento do processo de reprodução do capital.

A constituição e consolidação desta perspectiva na Geografia - na qual produção do espaço corresponde necessariamente à acumulação de valor -, à luz da recente crise mundial, suscitam questionamentos quanto à potência do setor imobiliário saciar o capital financeiro autonomizado em sua busca pela riqueza social. Nessa direção, é premente refletir sobre as formas do valor se valorizar (acumulação) e negar a si mesmo (crise) na produção do espaço e as formas de manifestação (aparência) e dominação que assume tal contradição, daí a possibilidade de problematizar a reprodução do espaço como reprodução ampliada do capital.

\section{A TEORIA E O PROBLEMA}

Os conceitos de crise e crítica, tão caro a este projeto de pesquisa, são empregados aqui no sentido marxiano, portanto, referem-se às contradições que o capital impõe a si mesmo. 0 capital ao mesmo tempo em que se põe e repõe, positiva e nega simultaneamente a sua existência, crise e acumulação são dois pares indissociáveis instaurados no seu âmago (ALFREDO, 2010). O conceito de crise está para além de uma negatividade em geral, banal, deve ser considerado como uma negatividade imanente, força motriz da dinâmica do capitalismo que, ao tender a superar seus limites, instaura novas contradições, por isso tal conceito é imprescindível para compreender o modus operandi da sociedade capitalista (GRESPAN, 1999). Daí trata-se de entender a crítica, assevera Lefebvre (200-), não como algo externo, moralizante, filantrópica ou humanista, senão como uma forma de expor a crítica interna que o sistema faz a si mesmo.

Assim, enfatiza Marx (1988, 1 I, p. 27), o seu método dialético tem no entendimento positivo do existente ao mesmo tempo o da sua negação. Ao apreender cada forma no fluxo do seu 
movimento contraditório, Marx desenvolve o conceito de capital a partir das categorias mais gerais e abstratas, aquelas que se revelam comum ao capital de toda a sociedade, o "capital em geral", antes de chegar às formas mais concretas da concorrência, dos juros, das crises e do mercado mundial (Rosdolsky, 2001). O caminho da exposição, diz Grespan (2002), é o do concrescer, em que as determinações abstraídas do seu todo vão constituindo a totalidade concreta enquanto síntese de múltiplas determinações, como escreve Marx sobre seu método (1982). As formas mais simples contêm o germe de toda a natureza da árvore ${ }^{9}$, portanto, ao longo da obra, esta semente antes encoberta vai se descobrindo e desenvolvendo o conceito. As formas mais ricas e complexas, no entanto, retroagem sobre as iniciais e redefinem o seu papel (GRESPAN, 2002). Este método de exposição deixa entrever desde o Livro I de O Capital, na seção da mercadoria, as premissas da autonomização do dinheiro e do desenvolvimento das forças produtivas que levará às crises da reprodução capitalista.

$\mathrm{Na}$ análise da forma mercadoria (Livro I), Marx abstrai, por um momento, do valor de uso e do caráter útil que a compõe, portanto, das suas diferentes formas concretas, restando a ela apenas a propriedade de ser produto do trabalho humano igual. Esta "objetividade fantasmagórica, simples gelatina de trabalho humano indiferenciado", como dispêndio físico e mental, sem consideração com a forma pela qual foi despendida, é a "substância social" comum a todas as mercadorias (Marx, 1 I, 1988, p. 47). Tal substância, o trabalho abstrato, é o que permite um valor de uso possuir valor, sendo a grandeza deste valor medida a partir do quantum de trabalho contém cada produto. A existência fisiológica do trabalho abstrato é a condição efetiva para a constituição do valor, que se torna de fato objetivo com as condições sociais da produção privada de mercadorias, ou seja, a produção destinada à troca (Grespan, 1999, p. 64-65). Nesta relação, o tempo de trabalho despendido na produção, que determina o valor dos produtos, aparece na proporção a ser trocada entre as mercadorias, ou na forma mais desenvolvida, é representado pela forma-monetária, o que virá a ser o dinheiro.

9. Trecho com alterações no qual Hegel trata da objetivação do espírito (1995). 
Da oposição na natureza da mercadoria - entre valor de uso e valor -, fruto do duplo caráter do trabalho - por um lado, dispêndio abstrato de força de trabalho e, por outro, dispêndio útil de trabalho adequado a um fim, destinado a criar valores de uso, decorre a formulação de Marx (1 I, 1988) sobre o desenvolvimento das forças produtivas - progresso nos materiais, máquinas, métodos e técnicas de produção -, desdobrada pelo autor no Livro III de O Capital como a "Lei da queda tendencial da taxa de lucro". A força produtiva se refere ao trabalho útil concreto, que torna-se uma fonte maior ou menor de produtos na proporção direta das mudanças na primeira. A riqueza material cresce numa proporção inversa à grandeza de valor dessa massa quando se encurta o tempo de trabalho necessário para a produção de cada produto. A possibilidade de redução a um mínimo de trabalho abstrato por unidade de mercadoria, ou seja, a substituição do trabalhador por máquinas, como argumenta Kurz (2002) diante da Revolução Microeletrônica, aponta para a possibilidade de crise com a redução da fonte de valor do capital.

A lei da taxa decrescente de lucro, expressão da produtividade aumentada do trabalho, significa que uma parte alíquota cada vez menor do capital global seja despendida em trabalho vivo, fonte de valor, o que leva esse capital a absorver cada vez menos mais-valia proporcionalmente ao seu volume. A queda da taxa de lucro se refere à diminuição relativa do componente variável do capital - trabalho - em relação ao constante - máquinas e matérias-primas -, tendência que Marx chama de elevação da composição orgânica dos capitais. O capital subsume a si todas as condições de sua reprodução e acumulação - capital constante e variável -, constitui-se, então, como um sujeito automático e, no seu movimento de autovalorização, revela a sua contradição fundamental, a saber, negar e afirmar simultaneamente o trabalho. O capital falha, portanto, ao buscar estabelecer uma medida coerente para si com referência à sua finalidade de produzir valor pelos próprios métodos utilizados, o que resulta, diz Grespan (1999), na desmedida para consigo mesmo; o capital nega a si ao negar o trabalho do qual depende.

A celeuma sobre a teoria das crises contidas em Marx é longa, como analisam Mantega (1976) e Prado (2013), frequentemente opondo autores em torno da lei tendencial da queda nas taxas de lucro, como a polêmica entre Cogoy e Swezy (1977), por isso a necessidade de uma incursão bibliográfica mais longa sobre o assunto, o que não cabe neste artigo. Aqui foi proposto, de maneira breve, resgatar nas obras mencionadas a leitura particular das crises 
capitalistas na sua correspondência com a produção do espaço, muitas vezes mais atrelada ao fluxo formal do capital (PRADO, 2012) e suas possíveis interrupções geradoras de crise, do que ao movimento interno e lógico das categorias que tenderiam a culminar com a crise do trabalho. Ainda sobre as crises, não foram abordadas as soluções tidas como idealistas para uma interpretação marxiana que não abandona a dialética -, presentes no discurso estatal e nas classes de investidores, que desconsideram a natureza imanente das catástrofes próprias de um sistema contraditório que cria leis sociais aparentemente naturais, portanto, agem de maneira inexorável e férrea como as leis da física (Marx).

Não obstante este esforço teórico e metodológico de apreensão do objeto, que é social e histórico, propõe-se cotejar a teoria com as recentes transformações no setor produtivo da construção civil, mais especificamente o setor habitacional na cidade de São Paulo. À semelhança de muitos autores que abordaram os percalços e a particularidade da industrialização brasileira, o debate em torno da produção na construção civil igualmente vai criar linhas interpretativas para compreender a baixa produtividade e composição orgânica dos capitais no setor, nomeadamente quando comparado com o inverso disto na Europa e EUA (MOURA, 2011; AMORIM, MELLO, 2009). Vilella (2007), em um levantamento exaustivo, descreve algumas vertentes que abordaram o setor como atrasado, ou resultante de uma acumulação via combinação arcaico - moderno, outros autores propuseram uma passagem linear de uma produção tradicional para manufatureira em seguida industrial, se opondo àqueles que entendem o desenvolvimento como desigual e combinado. Sem pormenorizar o tema, é consensual, como constata este e outros pesquisadores e especialistas já citados, as profundas transformações na produção propriamente dita na construção civil nos últimos vinte anos, em especial no subsetor de edificações, progressivamente mais racionalizado e industrializado. Os exemplos a seguir são emblemáticos: "Com a adoção de pré-fabricados, paredes e lajes de concreto e estruturas metálicas, casas populares podem ficar prontas, com entrega de chaves, em 20 dias", diz Vasquez, professora da Escola Politécnica da UFRJ; "A montagem funciona como o encaixe de peças de Lego", diz Hélio Dourado, presidente da construtora Premo; com a adoção dos novos métodos o número de funcionários cai entre 40\% e 50\%, afirma Carlos Borges, diretor de operações da Gafisa (incorporadora e construtora) (LAGE, 2010). 
$\mathrm{Na}$ direção de um revolucionamento das forças produtivas no setor da construção, cujas manifestações empíricas vão desde a formação de grandes monopólios altamente capitalizados e capital intensivos, ao trabalhador que monta no canteiro de obras os elementos já fabricados alhures, intenciona-se problematizar a concepção de que a produção do espaço constituiria uma saída para os capitais em crise. Com base nos autores mencionados (Harvey, Lefebvre, Smith, Carlos, Botelho, Tone, entre outros) e a partir do desdobramento do conceito de capital presente inclusive nas suas obras, é traçado no próximo item algumas formas de manifestação das leis e tendências efetivas nas outras esferas da produção em sua particularidade também na produção do setor imobiliário, ou seja, a tendência de crise fundamentada pela negatividade do capital não deixa de fora o setor imobiliário. Antes, porém, é preciso ainda algumas considerações sobre a relação contraditória entre preço e valor, assim como o distanciamento da forma monetária da sua materialidade inicial.

As simples constatações de lucros vultosos pela mera ascensão dos preços dos imóveis e a busca rápida por colher a renda que daí brota oculta o conteúdo das formas fenomênicas. A aparência superficial dos fenômenos nega, vela, a essência das relações sociais e nessa contradição essência-aparência, fruto da inversão do sujeito com o objeto, Marx elaborou o seu conceito de fetiche. Assim, perscrutar os altos preços dos imóveis, chamarizes para os investidores, deve levar a indagar se esta escalada progressiva não obnubila a quantidade real de trabalho que compõe as mercadorias produzidas, em um momento de intensos investimentos em máquinas e equipamentos em detrimento do trabalho vivo. $\mathrm{O}$ alto preço dos produtos imobiliários muito mais relacionados ao montante de dinheiro disponível em circulação (ALFREDO, 2010), sem lastro proporcional em trabalho, faz surgir da circulação, com força tanto maior quanto mais se considera o aumento da composição orgânica, o dinheiro através do dinheiro (D- $\left.D^{\prime \prime}\right)$, processo semelhante à especulação do setor financeiro. Outro elemento crítico do capital se refere aos custos com trabalho improdutivo, no caso específico do imobiliário diz respeito à corretagem, marketing, administração, logística, etc., que, segundo Marx, não criam valor, pois apenas medeiam a metamorfose formal das mercadorias - passagem M (mercadoria) a D (dinheiro) - e se apropriam da mais-valia gerada socialmente, são custos sociais (KURZ, 2002, MANDEL, 1982). Ainda com relação à incongruência entre preço e valor, Marx diz que é a forma mais adequada à socialização das 
mercadorias (Marx, 1 I, 1988); o preço é uma linguagem a expressar a substância valor para a subjetividade cotidiana dominada pelo fetiche (ALFREDO, 2010). É por intermédio dos preços de mercado das mercadorias, que já não coincidem com o valor de cada produto, que os capitais buscarão seu lucro, por isso quanto maior for o capital mais ele açambarcará a riqueza socialmente produzida (GRESPAN, 2011). Ora, isso suscita o problema de pensar o preço autonomizado da produção real de valor mediante a exploração do trabalho e as categorias que repartem o valor a partir dele: lucro/juro, a renda e o salário. $\mathrm{Na}$ "Fórmula Trinitária" Marx expõe que não há diversas fontes produtoras de valor, como a terra e o capital, mas a fonte da riqueza social é o trabalho. Logo, considerando a redução paulatina do trabalho proporcionalmente ao capital investido com o aumento da produtividade e a produção alavancada pela financeirização e crédito, é preciso pensar as novas determinações da renda da terra e do juro do capital financeiro nesse momento da reprodução capitalista.

É importante retomar a já citada apresentação dialética em O Capital, que vai do abstrato ao concreto, com vistas à resgatar a atualidade da teoria monetária de Marx desenvolvida desde o livro I. Sobre a sua teoria, ele mesmo disse: "Menos do que qualquer outro, o meu ponto de vista, [...] pode tornar o indivíduo responsável por relações das quais ele é, socialmente, uma criatura, por mais que ele queira colocar-se subjetivamente acima delas (1988, I 1, p. 19)". Nessa direção, às críticas morais e de cunho punitivo contra as personificações do sistema financeiro - os altos executivos, por exemplo - ou ainda àquelas que defendem a "mão visível do Estado" regulando as atividades bancárias como uma saída para a estabilidade (DOSSIÊ 2008, 2010), desconsiderando os próprios limites do Estado, inexoravelmente dependente da acumulação e dos mecanismos de endividamento (KURZ, 2002; 2004), propõe-se contrapor uma leitura que apreende o protagonismo financeiro não como excrescência, mas sim imanência da produção de mercadorias.

A primeira figura da autonomização do dinheiro se dá na sua função como medida de valor das mercadorias. A generalização da troca fixa no dinheiro - inicialmente no metal e mais tarde nas cédulas de papel - a forma equivalente a todo o mundo das mercadorias. Sem lembrar que ele emprestava o corpo para expressar a quantidade de valor que um produto possuía por também conter trabalho e, por isso, poder permutar-se com uma coisa distinta de si, a forma monetária é naturalizada e apaga a relação social que a engendrou. Paulani 
(2011) recupera as três determinações do dinheiro em Marx - medida de valor, meio de circulação e meio de pagamento - para demonstrar, logicamente, como que esta forma social vai prescindindo do próprio corpo material - produto do trabalho - quanto mais se afirma, haja visto o seu uso apenas ideal, como representante do trabalho social, em muitas transações do mercado em que não precisa estar presente. O vínculo material se torna ainda mais tênue, diz a autora, com o capital portador de juros. Nesta função de mercadoria, o dinheiro ao gerar um rendimento (juro) direto ao seu proprietário parece ele próprio produzir valor, sem precisar adentrar na produção de mercadorias. Esta aparência se torna real com o capital fictício, que leva ao paroxismo essa contradição, pois gera dinheiro sem passar pelo árduo comprometimento com a esfera produtiva, criadora de valor.

Não obstante essa potência fetichista de produzir valor por si só que o dinheiro possui, tal esfera financeira não é o bastante, por isso o levantamento do setor da construção deverá avaliar a sua determinação na produção do espaço. No ímpeto de valorização, o capital produzirá o espaço urbano e mobilizará o lucro, os juros e a renda da terra na tentativa de açambarcar a riqueza social, portanto, na sua crise, "o capitalismo só se manteve estendendo-se ao espaço inteiro" (LEFEBVRE, 200-, p. 71), reproduzindo as relações sociais de exploração e dominação. Assim, cabe questionar o discurso oficial, dos empresários e instituições financeiras, contidos em publicações referidas ao longo deste texto, ancorados no "bem comum", na dignidade humana, no desenvolvimento social e econômico através da produção habitacional. As empresas altamente capitalizadas, associadas aos ativos lastreados em imóveis, impõem que o produto imobiliário deve ser produzido segundo os imperativos de alta rentabilidade e liquidez, como as aplicações no mercado financeiro (FIX, 2007). São Paulo, de modo análogo à especulação que acontece no mercado financeiro, é mapeada e dividida com a formação do banco de terrenos das grandes construtoras sob as expectativas de estar no caminho da valorização. Garantido pelas políticas públicas, conforme, por exemplo, o Programa Minha Casa, Minha vida, formulado em conjunto com o grupo das 13 maiores construtoras do setor (TONE, 2010; ARANTES, FIX, 2009), o crescimento do setor imobiliário reiterou a segregação sócio espacial histórica, para não mencionar os problemas arquitetônicos, urbanísticos e de engenharia das moradias das classes de menor poder aquisitivo. Se de um lado a cidade é produzida em escala metropolitana diante do ímpeto dos capitais ociosos em busca de valorização, no plano do 
cotidiano o indivíduo é dominado pelo capital financeiro mediante a promessa do trabalho futuro com o endividamento pelo "sonho da casa própria".

\section{À GUISA DE RESULTADOS: PRIMEIRA ANÁLISE DE UMA PESQUISA EM ANDAMENTO}

Certamente, é possível contabilizar as cifras do lucro empresarial, mensurar por metros quadrados ou quantificar em volume de concreto a multiplicação de canteiros de obras observáveis imediatamente na paisagem paulistana, sem que estes fenômenos, contudo, sejam revelados como forma de manifestação da essência a ser descoberta. O mundo corriqueiro e cotidiano, autoevidente, é um "claro-escuro", diz Kosik (1995), onde a essência aparece de modo inadequado, parcial, contrária mesmo ao que é, mas também é a mediação que indica a própria essência. A realidade, como assevera o autor, é a unidade entre o fenômeno (aparência) e a essência, portanto, não há uma total independência ou indiferença entre ambos, pelo contrário, nesta união dialética há uma relação íntima, através da qual o fenômeno imediato, em sua ordem externa e passível de ser descrito e quantificado, pode ser revelado como forma de manifestação das leis essenciais.

Propõe-se ultrapassar a dimensão meramente fisicalista da realidade, reduzida à extensão, quantificação e mensurabilidade sem, porém, cair em especulação vazia. $O$ todo rico e concreto não é acessível de imediato, é necessária a mediação da parte, sem, contudo, diz Lukács (2012), explicá-las no seu mero isolamento ou relacionar externamente instâncias organicamente interligadas, deve-se reportar cada momento à totalidade. Tal método pressupõe a investigação empírica, a análise minuciosa do objeto, abstraindo do todo de determinações as frações a ele ligadas internamente para compreender as suas formas de desenvolvimento e os nexos mútuos entre parte e todo. Desse modo, concebe-se que é possível articular o desenvolvimento das forças produtivas na indústria da construção civil, as formas de dominação e exploração, a financeirização do setor, as mudanças jurídicas para a produção imobiliária e a participação do Estado via políticas públicas e incentivos, buscando compreendê-los racionalmente como novas configurações decorrentes da mais recente mudança qualitativa na reprodução capitalista. Obviamente o resultado concreto desta análise não está neste artigo, mas acredita-se que foram lançadas aqui as bases teóricas e metodológicas, bem como um primeiro esboço da pesquisa que vem tomando corpo. 
Deve-se notar que neste momento do texto há uma aproximação analítica sem abandonar o fundamento abstrato da realidade empírica. Na maior parte da discussão acima, o princípio negativo e universal do capital - a crise - o é enquanto potência, ou seja, contradição comum ao capital em geral, mas que na realidade só vem a ato mediante a particularidade; não pode existir como abstração e sim como um capital determinado ${ }^{10}$. 0 capital realiza a sua natureza, o seu conceito, a saber, a autovalorização, através de sucessivas configurações; o desdobramento do capital se efetiva pela formação social (sucessão de formas, transfigurações) $)^{11}$. Cabe à pesquisa desvelar a relação dialética entre o universal e o particular, portanto, não partir de nenhum resultado a priori, mas perscrutar analiticamente a crise no concreto que, aqui, é assumido como a produção habitacional no mercado imobiliário paulistano interligada ao processo de financeirização do setor e às políticas de incentivo ao seu desenvolvimento, com os consequentes efeitos na vida cotidiana da metrópole. Nessa direção, expõe-se brevemente alguns dados das recentes transformações nas frações do capital da construção civil, pois entendemos que só depois de analisar o movimento das partes em questão é possível reproduzir os fenômenos enquanto concreto pensado, ou melhor, como totalidade rica e estabelecida por múltiplas determinações (MARX, 1982, p. 14).

O comemorado "boom" da construção civil pelo empresariado nacional ${ }^{12}$ se estendeu por todo um macro setor com inúmeras complexidades ${ }^{13}$ e teve um efeito multiplicador sobre o

10. "Se não existe uma produção em geral, também não pode haver produção geral. A produção é sempre um ramo particular da produção - por exemplo, a agricultura, a pecuária, a manufatura etc. -, ou ela é totalidade" (MARX, 1982, p. 5).

11. Aqui ressoa o método dialético de Hegel na apresentação do conceito do capital em Marx. "O primeiro que advertimos é que aquilo que denominamos princípio, fim último, determinação, ou o que o espírito em si é, a sua natureza, o seu conceito - é apenas algo de universal e de abstracto. O princípio, a lei é algo de universal e interno que, como tal, por verdadeiro que em si seja, não é de todo efectivamente real. (...) Tem de ocorrer um segundo momento para a sua realidade efectiva, e tal momento é a actuação, a realização, cujo princípio é a vontade, a actividade dos homens no mundo em geral. Só graças a esta actividade é que se realizam os conceitos e as determinações em si existentes (HEGEL, 1995, p. 74)". Sobre isso ver também Rosdolsky (2001), Grespan (1999) e Muller (2010).

12. Desde o "Milagre Econômico" e do já extinto BNH (Banco Nacional da Habitação) a construção civil no Brasil não se desenvolveu tanto quanto nos últimos quatro anos - de 2004 a 2007 -, declarou João Cláudio Robusti, então Presidente do SindusCon (Sindicato da Construção), vice-presidente da CBIC (Câmara Brasileira da Indústria da Construção) e diretor de Habitação, Saneamento e Infra-Estrutura da Fiesp (Federação das Indústrias do Estado de São Paulo) (ROBUSTI, 2008). 
emprego $^{14}$ e as receitas desta ampla cadeia produtiva, que é responsável por algo em torno de $16 \%$ do PIB nacional (MEIRELLES, 2007) ${ }^{15}$. Os dados do PAIC (Pesquisa Anual da Indústria da Construção) ${ }^{16}$ de 2010 (v. 20) ilustram com cifras o otimismo do empresariado ${ }^{17}$. Os três subsetores que compõem o relatório anual apresentaram, no decorrer de 2007 e 2010, uma variação positiva nominal de ao menos $97 \%$ cada um no valor adicionado da construção, são eles (os valores devem ser multiplicados por 1.000): construção de edifícios, de $\mathrm{R} \$$ 25.454.696 para $\mathrm{R} \$$ 50.140.453; obras de infraestrutura, de $\mathrm{R} \$ 25.685 .161$ para $\mathrm{R} \$$ 50.620.551; serviços especializados para construção, de $\mathrm{R} \$ 1$ 12.199.905 para $\mathrm{R} \$$ 24.337.935. No ano de 2011 o valor total das incorporações, obras e/ou serviços atingiu os $R \$ 286,6$ bilhões, um aumento real de $63,1 \%$ em relação ao ano de 2007 , assinalando um crescimento contínuo. Neste mesmo ano, o segmento residencial efetivou obras no valor de $\mathrm{R} \$ 51,7$ bilhões, com uma participação de $22 \%$ do total supracitado, sendo os edifícios residenciais os produtos de maior relevância, contribuindo com 18,8\% (PAIC, 2011, v. 21). Este crescimento acelerado, embora tenha distribuído os capitais da construção civil nos diversos estados brasileiros, está em grande medida concentrado na Região Sudeste, no Estado de São Paulo, nomeadamente na sua capital. Do total de empresas ativas formais e do seu

13. Este macro setor envolve desde pequenas empresas informais produtoras de materiais de construção, trabalhadores autônomos prestadores de serviços até grandes grupos empresariais com alta produtividade e centralização de capitais na extração de matérias-primas, siderurgia, etc. A definição do que seria este vasto setor varia em diversos estudos, adota-se aqui aquela utilizada pelo IBGE na Pesquisa Anual da Indústria da Construção (PAIC), pois é uma das fontes mais utilizadas pelos órgãos oficiais e entidades de classe, além disso permite o acesso aos dados do setor em âmbito nacional, ao mesmo tempo em que a pesquisa disponibiliza informações desagregadas do segmento da construção de edifícios no último decênio. O referido estudo divide em três grandes ramos as empresas da construção civil: construção de edifícios, obras de infraestrutura e serviços especializados para construção, por sua vez subdivididos em 9 grupos e 21 classes.

14. Segundo Balanço do Mercado Imobiliário de 2012 realizado pelo Secovi-SP (Sindicato da Habitação), em 10 anos a construção civil participou com 9,8\% do total de empregos formais gerados no Brasil, ou seja, 1,7 milhão de empregos dos 17,6 milhões de postos de trabalho.

15. Já Mello e Amorim (2009, p. 390) citam dados da Fiesp de 2005 no montante de 13,8\%. O DIEESE (2001, p. 8) publicou relatório setorial no qual a participação em 1996 é de 14,8\%.

16. Foram pesquisados 8 volumes da Pesquisa Anual da Indústria da Construção (PAIC). No corpo do texto será citado o volume seguido do ano.

17. Os dados divulgados pela PAIC dizem respeito apenas à fração formal das empresas. Segundo estudo conjunto, publicado pela CBIC (Camara Brasileira da Indústria da Construção) e FGV (Fundação Getúlio Vargas) em 2009, o valor adicionado das empresas formais correspondeu à 63,5\% do total das empresas (formais e informais). Nesse mesmo ano, apenas 30,1\% dos trabalhadores da construção possuíam carteira assinada. 
correspondente montante em valores de incorporações, obras e/ou serviços junto aos postos de trabalho contabilizados no Brasil, referente ao ano de 2011, o Estado de São Paulo participa da seguinte forma: 14.083 (27,15\%) empresas ativas; 728.698 (28,81\%) postos de trabalho; $\mathrm{R} \$$ 99.092.720.000 (35,89\%) em valores de incorporações, obras e/ou serviços da construção $^{18}$. A cidade de São Paulo é responsável por grande parte destes números, como é possível notar na fração da construção civil foco deste projeto, o segmento residencial. A capital esta na frente de outras cidades, por ampla vantagem, no número de unidades residenciais disponíveis para comercialização, como também no de lançamentos e vendas para o período de 2012 e $2013^{19}$. Foram contabilizadas em média, nos anos de 2010 e 2011, 38 mil unidades residenciais lançadas, que somaram em valores líquidos $\mathrm{R} \$ 36$ bilhões (SECOVI, 2012).

O crescimento sem precedentes da Construção Civil levou especialistas e empresários a buscarem um nexo causal para o desempenho do setor, o resultado foi um diagnóstico quase em uníssono que apontava medidas de ordem legal e institucional que permitiram o afluxo de recursos do mercado de capitais para consumo e produção e aumentaram a segurança jurídica das empresas, bem como o protagonismo direto do Estado, ora com ações para elevar exponencialmente a disponibilidade de crédito via programas públicos ou bancos privados, ora através de contratações de obras, desonerações, redução da taxa de juros e projetos de incentivo à melhoria da qualidade e produtividade na construção civil ${ }^{20}$.

18. A comparação escalar entre as unidades consideradas - Brasil, Região Sudeste, Estado de São Paulo - só foi possível para o universo das empresas com 5 ou mais pessoas devido à disponibilidade de informações do PAIC. Segundo o relatório, o número de empresas ativas para o ano de 2011 (v. 21), incluindo as que empregavam de 1 a 4 pessoas, totalizavam 92.732, com mais de 2,6 milhões de empregos e um montante superior a $\mathrm{R} \$ 286,6$ bilhões em valores de incorporações, obras e/ou serviços da construção.

19. Os estados mais bem colocados em valores de incorporação, obras e/ou serviços da construção no anos de 2011 são, em ordem de importância: São Paulo, Rio de Janeiro e Minas Gerais (PAIC, 2011, v. 21). A comparação entre as capitais, no quesito unidades residenciais ofertadas, lançadas e vendidas, foi uma aproximação a partir dos dados elaborados pela CBIC (www.cbicdados.com.br).

20. Não cabe aqui elencar todos os fatores citados pelos empresários, entidades de classe, pesquisas acadêmicas e governo para explicar o desenvolvimento da indústria da construção, foram apresentados os de maior relevância segundo as próprias fontes. Entre os materiais consultados e que representam a opinião dos órgãos públicos, empresários e investidores, estão: CBIC (2011), PAIC - IBGE (2004 a 2011), Revista Conjuntura da Construção (publicada em conjunto pela FGV e o Sindicado da Construção de São Paulo, Sinduscon-SP), Revista Noticias da Construção (Sinduscon-SP), Revista do Sistema de Financiamento Imobiliário (publicação da Abecip - Associação Brasileira das Entidades de Crédito Imobiliário e Poupança), Revista O Empreiteiro, FGV (2007), SECOVI (2012). 
Certamente, pode-se alongar a lista das causas macro ou microeconômicas e mesmo das fontes que abordaram o problema, não obstante, no que tange à produção imobiliária residencial na capital paulista, objeto empírico desta proposta de investigação, é premente enfatizar o processo de financeirização que avança como uma alavanca a esta fração do capital e a atual política de crédito do Estado.

A porta entreaberta nos anos 1990 para a entrada do capital financeiro no setor imobiliário ${ }^{21}$ terminou por dar passagem mais completamente na segunda metade dos anos 2000. As novas formas de captação de recursos, dentre as quais se destacam os FII (Fundo de Investimento Imobiliário) ${ }^{22}$, a securitização com os CRI (Certificados de Recebíveis Imobiliários) $^{23}$ e as IPOs (InitialPublicOffering - Oferta Pública de Ações), sem mencionar as LCI (Letras de Crédito Imobiliário), debêntures ${ }^{24}$, fusões e a participação estrangeira direta ${ }^{25}$, ganham em aporte de capitais principalmente a partir de 2005 e superam qualquer período anterior, marcando o processo de financeirização da produção de imóveis em São Paulo ${ }^{26}$.

21. Faz-se menção à criação do Sistema de Financiamento Imobiliário (SFI), em 1997, que torna possível a financeirização do setor imobiliário, como apontam Botelho (2007), Fix (2007), Tone (2010) e Shimbo (2010). Segundo estudo da FGV (2007, p. 10), “o SFI tem como principais fundamentos a securitização dos créditos imobiliários e a maior segurança jurídica dos contratos".

22. Fundos constituídos para aplicar recursos no desenvolvimento de empreendimentos imobiliários, imóveis já prontos, títulos e valores mobiliários ligados ao mercado imobiliário.

23. A securitização é um processo pelo qual os créditos imobiliários são convertidos em títulos mobiliários. As incorporadoras e construtoras lançam no mercado este conjunto de dívidas mediante uma companhia securitizadora no intuito de recompor seu capital e fomentar novos lançamentos.

24. As LCI (Letras de Crédito Imobiliário) e as LH (Letras Hipotecárias) são os títulos mais usados, com lastro em créditos imobiliários, para captação de recursos pelos bancos e instituições financeiras. A debênture é outra forma de captação de recursos pelas empresas do setor imobiliário.

25. Tem sido amplamente noticiado a entrada de capitais estrangeiros e os processos de fusão. Ver, por exemplo: "País atraiu R\$10 bi em investimentos", Jornal O Estado de S. Paulo; "Setor imobiliário nacional atrai mais investidores estrangeiros", Estadão.com.br.; "Brascan e Company anunciam fusão no setor imobiliário", Folha Online; "Fundo Paladin, dos EUA, vai dividir controle da Inpar", Estadão.com.br; "Banco Morgan Stanley estréia em fundos imobiliários", Jornal Valor Econômico. As referências completas estão no final do projeto.

26. A sexta edição do "Anuário Uqbar: Securitização e Financiamento Imobiliário", de 2013, financiada por grandes empresas e prestadoras de serviços do ramo financeiro, oferece um histórico de todas as fontes de financiamento imobiliário no Brasil, sejam elas governamentais, bancários ou do mercado de capitais. Em 2012 registrou-se o sexto ano de alta consecutiva no mercado de $\mathrm{LCl}$, com $\mathrm{R} \$ 83,40$ bilhões em depósitos neste título. As emissões de debêntures experimentaram expressiva alta em 2007 e, apesar das irregularidades nos próximos anos, não voltaram mais aos patamares de baixa capitalização anteriores. As empresas do setor a tem utilizado em substituição à baixa oferta pública de ações, assim a retomada do seu crescimento em 2012. As ofertas de ações seguem em declínio deste os $\mathrm{R} \$ 12$ bilhões captados no ano de 2007. Já os Fll seguem em franca expansão, sendo emitidos quase R\$12 bilhões no ano de 2012. Os CRI 
As inovações estreitam os laços entre o setor financeiro e o imobiliário, desintermediando os financiamentos, antes centrados nos bancos, para a captação direta no mercado financeiro. A transformação dos ativos imobiliários de pouca liquidez em ativos mobiliários de grande liquidez, lastreados pelo imóvel, fomenta os negócios e dinamiza o setor imobiliário (BOTELHO, 2007; FIX, 2007; TONE, 2010). Tão importante quanto a capitalização das empresas é o financiamento ao consumo. Ainda que alguns dos instrumentos mencionados acima também cumpram com esta função, foi o crescimento do financiamento via SBPE (Sistema Brasileiro de Poupança e Empréstimo) e FGTS (Fundo de Garantia por Tempo de Serviço) até próximo ao seu esgotamento ${ }^{27}$, associado com o programa federal MCMV (Minha Casa, Minha Vida), que permitiu a expansão dos negócios para os capitais investidos no imobiliário. O dinheiro público proporcionou produção em escala para consumo de massas, garantiu elevadas taxas de retorno para as empresas, como bem demonstrou a migração de capitais para atender as classes até então desinteressantes para o mercado e a veiculação de quase a totalidade das verbas do MCMV para a promoção privada de moradias (FIX, ARANTES, 2009; SHIMBO, 2010). Propõe-se, assim, a entender o processo de reestruturação do financiamento imobiliário iniciado nos anos 1990 e que se estende até os dias atuais, como por exemplo, nas recentes propostas de elevar a relação financiamento imobiliário/PIB com novas formas de captação dos bancos e instituições financeiras junto ao mercado de capitais ${ }^{28}$, associado com as políticas de crédito para o setor, como o aumento do repasse das verbas do SBPE, FGTS e o programa MCMV. A intensa entrada de capitais

após chegarem perto dos $\mathrm{R} \$ 14$ bilhões em emissões no ano de 2011 , recuaram próximo dos $\mathrm{R} \$ 10$ bilhões em 2012 (UQBAR, 2013). O que há de comum no comportamento destes instrumentos, assim como nos recursos do SBPE, FGTS e repasses do governo federal, é o crescimento incomparável com os anos que antecedem a segunda metade da década de 2000.

27. Diversas pesquisas demonstram o sucessivo aumento de recursos do FGTS e do SBPE destinados ao financiamento habitacional. Os dois sistemas atingiram, em 2012 , respectivamente, $R \$ 33,810$ milhões e $\mathrm{R} \$ 82,561$ milhões. O governo federal destinou recursos para o financiamento habitacional também por meio do Orçamento geral da União, no montante de $R \$ 94,439$ milhões (UQBAR, 2013).

28. Em seminário internacional sobre financiamento habitacional e formas de captação promovido pela ABECIP, conclui-se que os recursos do FGTS e do SBPE estão próximo ao esgotamento. Para manter o crescimento da construção civil seria preciso elevar em nível do crédito imobiliário em relação ao PIB, nessa direção, os representantes da iniciativa privada e do poder público debatem sobre um novo instrumento, os covered-bonds (GARCIA, 2010). Segundo Silva (2010), estes instrumentos de divida são utilizados amplamente na Europa e têm como garantia os financiamentos imobiliários, empréstimos ao setor público ou financiamentos garantidos por navios. Eles seriam mais seguros para os investidores do que outras formas de captação, por isso a possibilidade de implementar com êxito no Brasil. 
teria tirado o Brasil da "Idade da Pedra" e proporcionado avanços sociais na direção da casa própria, dizem os empresários e investidores, o antes atrasado setor da construção civil, anos atrás predominantemente artesanal, tem se tornado progressivamente mais produtivo e centralizado. Entender a liberalização do mercado imobiliário e a entrada massiva dos capitais no setor, associada com as políticas de Estado garantidoras do consumo/lucros, é parte imprescindível para compreender outros dois movimentos do setor em questão, a saber, analisar como estas medidas impulsionaram o desenvolvimento das forças produtivas na construção civil e quais foram elas, e desvelar as novas formas de dominação do trabalho na produção propriamente dita da mercadoria habitação, sob os imperativos de alta produtividade e renovados métodos de gestão, atrelados a subsunção do cotidiano na metrópole, que passa a ser controlado e planejado através das expectativas de rentabilidade por parte dos acionistas e investidores com o aval do Estado.

Cabe, portanto, refletir se a circulação dos capitais ociosos das esferas financeiras para a produção do espaço, via setor imobiliário, funcionam como uma força impulsora a realizar a lei geral da acumulação capitalista na construção civil, apresentada por Marx (1 II, 1988) como sendo o desenvolvimento da produtividade do trabalho - a mais potente alavanca da acumulação -, o que implicaria na execução das contradições que a acompanham. 0 atual cenário da construção civil brasileira contrasta com o panorama do setor até os anos 1980, que se consolidou sobre formas tradicionais de administração (empresa familiar) e produção (focada na habilidade manual do trabalhador), baixa qualidade dos materiais e componentes, insuficiente divisão social do trabalho e uso extensivo da força de trabalho de pouca qualificação. Parece que há um movimento de centralização das empresas em decorrência do processo de financeirização e da participação do Estado acima mencionados, acirrando a concorrência no interior deste ramo produtivo; a disputa pelas obras, novas oportunidades de negócios, a tentativa de baratear o preço do produto final e reduzir os custos são as formas deste movimento de centralização, no qual os pequenos capitais são derrotados pelos grandes (MARX, 1 II, 1988) ou restam a eles as parcelas que não interessam aos monopólios (MANTEGA, 1976). O resultado observado tem sido a incorporação da ciência e da técnica à serviço da produtividade e a formação de grandes empresas - que agora detêm a função de construtora, incorporadora, proprietária fundiária, intermediária entre o consumidor e o Estado, financiadora (SHIMBO, 2010) -, que têm acesso privilegiado 
aos financiamentos, materiais e ao trabalho mais qualificado (MOURA, 2011), assim como concentram a maior parte da riqueza social através da sua participação nos mercados.

Uma breve incursão nas estatísticas ilustra o panorama mencionado. O relatório do Paic de 2010 (v. 20) demonstra o avanço da centralização na indústria da construção, com o aumento da participação na produção por parte das grandes empresas (com mais de 250 pessoas ocupadas), de $47,8 \%$ para $52,8 \%$, em detrimento das pequenas e médias. Para o ano de 2011, as empresas da construção civil com mais de 500 pessoas ocupadas, representando 0,66\% das 92.732 empresas ativas formais, foram responsáveis por 38,95\% dos mais de $\mathrm{R} \$$ 286 bilhões em valores de incorporações, obras e/ou serviços e 33,88\% de um total maior que 2,6 milhões de trabalhadores ocupados. No setor construção de edifícios, observa-se igualmente a fragmentação do capital em pequenas empresas, que somam 20.231 , e a simultânea centralização dos negócios, pois 1,16\% das empresas com mais de 500 pessoas são responsáveis por $27,15 \%$ do pessoal ocupado (253.458 trabalhadores) e $28,69 \%$ dos valores de incorporações, obras e/ou serviços (mais de R\$ 28,4 bilhões) (PAIC, 2011, v. 21). Os reflexos da abertura de capital na bolsa por algumas empresas do setor também podem ser notados na elevada centralização dos capitais na RMSP (Região Metropolitana de São Paulo), como lembra Shimbo (2010). Os dados da Embraesp são de 2010: 2,7\% das incorporadoras (10 empresas) lançaram juntas 35,48\% das unidades em 2010 e foram responsáveis por 39,25\% do produto total, entre elas apenas 2 não tinham capital aberto; no caso das construtoras, no mesmo ano, 3,42\% (10 empresas) lançaram $28,86 \%$ das unidades e produziram $34,85 \%$ do produto total, entre elas só 3 não abriram seu capital. São estas grandes empresas constituídas que mais elevaram a sua produtividade, como aponta o documento do CBIC (2011). A PTF (produtividade total dos fatores) se elevou constantemente no período mensurado pela pesquisa, do ano de 2003 a 2009, isso significa que o valor adicionado superou os dispêndios com trabalho e capital. O progresso tecnológico permitiu a crescente produtividade; os investimentos em máquinas e equipamentos elevaram o valor adicionado por trabalhador e tem permitido a sua substituição em um momento de escassez de força de trabalho. No segmento de edificações, ramo diretamente ligado a esta pesquisa, o valor adicionado destas empresas se elevou à taxa de $19,2 \%$ ao ano, superior a do emprego, de $12,8 \%$ ao ano, e ao estoque de 
capital por trabalhador, de $7,6 \%$ ao ano, resultado explicado pelo aumento do valor adicionado acima da alta demanda por emprego e do aumento do capital por trabalhador. Interessa perscrutar a atual condição da produção habitacional no Brasil com vistas à refletir se a execução da lei geral da acumulação, com o uso de modernas técnicas, sistemas construtivos e avanços científicos, implicaria em contradições a negar o próprio ímpeto do capital de se valorizar, ou seja, ao perseguir seu destino de produzir mais valor o capital tenderia a si negar pelos seus próprios métodos. Daí pensar se os capitais ociosos em busca de valorização, ao mobilizar a propriedade privada urbana e o trabalho para sobrepujar suas barreiras, tende a superar sua crise ou generaliza suas contradições também nesse setor da produção e circulação social.

\section{BIBLIOGRAFIA}

ALFREDO, Anselmo. Modernização e Reprodução Crítica. Agroindústria do Leite e Contradições do Processo de Acumulação. In. GEOUSP Espaço e Tempo: Revista de Pós-Graduação em Geografia, São Paulo, n. 24, p. 63-108, 2008.

. Crise Imanente, Abstração Espacial. Fetiche do Capital e Sociabilidade Crítica. Terra Livre, n. 34, p. 37-62, 2010.

ALFREDO, A.; SILVA. A. C M. Modernização e contradições espaço-temporais. Centralidades e periferias na metrópole de São Paulo. Três momentos, um percurso: aldeamentos indígenas, industrialização e periferia urbana. Boletim Paulista de Geografia, v. 91, p. 159-188, 2011.

AMORIM, S. R. L de; MELLO, L. C. B de B. O Subsetor de Edificações da construção civil no Brasil: uma análise comparativa em relação à União Européia e aos Estados Unidos. Revista Produção, São Paulo, v. 19, n. 2, p. 388-399, maio/ago. 2009.

ARANTES, Pedro; FIX, Mariana. Como o governo Lula pretende resolver o problema da habitação. Alguns comentários sobre o pacote habitacional Minha Casa, Minha Vida. Correio da Cidadania, 30 de julho de 2009. Disponível em: $<$ http://www.correiocidadania.com.br/index.php?option=com_content\&view=category\&layout= blog\&id=66\&ltemid=171>. Acessado em: 20/06/2013.

BORÇA Junior, Gilberto Rodrigues; TORRES Filho, Ernani Teixeira. Analisando a crise do subprime.Revista do BNDES, Rio de Janeiro, v. 15, n. 30, p. 129-159, Dez. 2008.

BOTELHO, Adriano. O urbano em fragmentos: a produção do espaço e da moradia pelas práticas do setor imobiliário. São Paulo: Annablume, Fapesp, 2007.

BRAGA, José Carlos de S. Financeirização global: o padrão sistêmico de riqueza do capitalismo contemporâneo. In: FIORI, J. L.; TAVARES, M. da C. (Org.). Poder e Dinheiro: uma economia política da globalização. 6 ed. Petrópolis: Vozes, 1998. 
CBIC - Câmara Brasileira da Indústria da Construção. A produtividade da construção civil brasileira. Brasília, 2011, p. 1-34. Disponível em: < http://www.cbicdados.com.br/menu/estudosespecificos-da-construcao-civil/produtividade-na-construcao-civil>. Acessado em: 14/12/2013.

CARLOS, Ana Fani. São Paulo: do capital industrial ao capital financeiro. In: CARLOS, A. F. A.; OLIVEIRA, A. U (Org.). Geografias de São Paulo: a metrópole do século XXI. São Paulo: Contexto, 2004.

COGOY, Mario; SWEEZY, P. M. Teoria da Acumulação Capitalista. Porto: Escorpião, 1977.

COUTO, Luccas Ribeiro do. "Nem só o que é sólido se desmancha no ar: a Nova Luz na produção insubstancial do espaço urbano". 202 f. Dissertação (Mestrado em Geografia Humana) Faculdade de Filosofia, Letras e Ciências Humanas, Universidade de São Paulo, São Paulo, 2011.

DIEESE. Os trabalhadores e a reestruturação produtiva na construção civil brasileira. Estudos Setoriais. no 12. São Paulo: DIEESE, 2001.

DOSSIÊ da Crise. Associação Keynesiana Brasileira. Disponível em: http://www.ppge.ufrgs.br/akb/, 2008.

DOSSIÊ da Crise II. Associação Keynesiana Brasileira. Disponível em: http://www.ppge.ufrgs.br/akb/, 2010.

EMBRAESP - Empresa Brasileira de Estudos de Patrimônio. São Paulo, 2010. Ranking Imobiliário. Disponivel em: < http://www.embraesp.com.br/176/RankingImobiliario.aspx?pageid=176\&\%3fnavid=108>. Acesso em: 18/02/2014.

ESTADÃO.COM.BR. "Setor imobiliário nacional atrai mais investidores estrangeiros". Disponível em: $\quad$ http://www.estadao.com.br/noticias/economia,setor-imobiliario-nacional-atrai-maisestrangeiros,167413,0.htm>, 2008. Acessado em: 20/08/2013.

ESTADÃO.COM.BR. "Fundo Paladin, dos EUA, vai dividir controle da InPar". Disponível em: <http://www.estadao.com.br/noticias/impresso,fundo-paladin-dos-eua-vai-dividir-controle-dainpar,297952,0.htm>, 2008. Acessado em: 20/08/2013.

FIX, Mariana. São Paulo cidade global: fundamentos financeiros de uma miragem. São Paulo: Boitempo, 2007.

FOLHA ONLINE. Brascan e Company anunciam fusão no setor imobiliário. Disponível em: <http://www1.folha.uol.com.br/mercado/2008/09/443542-brascan-e-company-anunciam-fusaono-setor-imobiliario.shtml>, 2008. Acessado em: 20/08/2013.

FUNDAÇÃO GETÚLIO VARGAS. O crédito imobiliário no Brasil, caracterização e desafios. São Paulo: FGV, março de 2007, p. 1-48.

GARCIA, Marcos. Uma nova opção para o funding imobiliário. Revista Sistema de Financiamento Imobiliário, São Paulo - Abecip, Ed. 32, 2010, p 19-38.

GRESPAN, Jorge L. S. O Negativo do Capital. São Paulo: Hucitec, 1999.

. A dialética do avesso. Crítica Marxista, n. 14, p. 26-37, 2002.

As formas da mais-valia: concorrência e distribuição no Livro III de O Capital. Critica Marxista, n. 33, p. $9-30,2011$. 
HARVEY, David. Condição Pós-Moderna. Trad. Adail U. Sobral; Maria S. Gonçalves. 14. ed. São Paulo: Ed. Loyola, 2005a.

. A produção Capitalista do Espaço. São Paulo: Annablume, 2005b.

. A Liberdade da Cidade (Trad. Anselmo Alfredo, Tatiana Schor, Cássio Arruda Boechat). GEOUSP - Espaço e Tempo, São Paulo, № 26, pp. 09 - 17, 2009.

O enigma do capital: e as crises do capitalismo. Trad. João Alexandre Peschanski. São Paulo: Boitempo, 2011.

Loyola, 2012.

O Novo Imperialismo. Trad. Adail U. Sobral; Maria S. Gonçalves. 6 ed. São Paulo: Ed.

HEGEL, Georg Wilhelm F. A razão na história: introdução a filosofia da historia universal. Trad. Artur Morao. Lisboa: Edições 70, 1995.

KOSIK, Karel. Dialética do Concreto. Rio de Janeiro: Paz e Terra, 1995.

KURZ. A ascensão do dinheiro aos céus. Disponível em: <http://planeta.clix.pt/obeco/>. (Versão Portuguesa), 2002. Acessado em: 30/02/2014.

As perfídias do capital financeiro. 1a parte. Disponível em: <http://obeco.planetaclix.pt/robertkurz.htm>, 2003. Acessado em: 30/02/2014.

- A falta de autonomia do Estado e os limites da política: quatro teses sobre a crise da regulação política. In. Com todo vapor ao colapso. Juiz de Fora: UFJF: Pazulin, 2004.

LAGE, Janaina. Construtoras fabricam 'casas a jato'. Folha de São Paulo, Mercado, São Paulo, 31/10/2010.

LÉFÈBVRE, Henri. A Revolução Urbana (Trad. Sérgio Martins). Ed. UFMG, Belo Horizonte, 2004.

. Espaço e Política. O Direito à cidade II. Trad. Margarida Maria de Andrade e Sérgio Martins. [S.I.]. [200-].

LÊNIN, Vladimir Ilitch. Imperialismo. Fase Superior do Capitalismo (Ensaio Popular). In: Obras Escolhidas. vol. 1. São Paulo: Alfa Ômega, 1986, p. 575-671.

LUKÁCS, Georg. História e Consciência de Classe. Estudos sobre a dialética marxista. Trad. Rodnei Nascimento. 2o Ed. São Paulo: Martins Fontes, 2012.

MANDEL, Ernest. A expansão do Setor de Serviços, a "Sociedade de Consumo" e a Realização da Mais-Valia. In: Capitalismo Tardio. São Paulo: Abril Cultural, 1982.

MANTEGA, Guido. A lei da taxa de lucro: A Tendência da Queda ou a Queda da Tendência? Estudos Cebrap, São Paulo, n. 16, p. 28-64, abril-junho 1976.

MARX, Karl. Para a crítica da economia política. Trad. EdgardMalagodietalli. In. Para a critica da economia política; Salário, preço e lucro; O rendimento e suas fontes. São Paulo: Abril Cultural, 1982.

O Capital. Crítica da Economia Política. Livro 1, 2 e 3. Trad. Régis Barbosa e Flávio R. Kothe. São Paulo: Abril Cultural, 1988.

MEIRELLES, Henrique. Crédito Imobiliário e Desenvolvimento Econômico. Revista "Conjuntura da Construção", ano V, no 4, p. 5, dezembro de 2007. 
MOURA, André D. S. de. Novas formas, velhas contradições: a dinâmica cíclica da industrialização em sua forma canteiro. 290 f. Dissertação (Tecnologia da Arquitetura) - Faculdade de Arquitetura e Urbanismo, Universidade de São Paulo, São Paulo, 2011.

MÜLLER, Marcos Lutz. Exposição e Método Dialético em "O Capital". Disponível em: <http://orientacaomarxista.blogspot.com.br/2010/10/exposicao-e-metodo-dialetico-em-o.html>, 2010. Acessado em: 30/02/2014.

O ESTADO DE SÃO PAULO. Prêmio Top Imobiliário, São Paulo, 14/06/2013. Especial, H16, p. 65.

PAULANI, L. M. A Autonomização das Formas Verdadeiramente Sociais na Teoria de Marx: comentários sobre o dinheiro no capitalismo contemporâneo. Economia (Brasília), v. 12, p. 49-70, 2011.

. O Brasil na crise de acumulação financeirizada. In. Anais do IV Encuentro Internacional de Economia Política y Derechos Humanos, del 9 a 11 de septiembre de 2010.

PAIC - Pesquisa Anual da Indústria da Construção. Volumes. 14, 15, 16, 17, 18, 19, 20 e 21. Rio de Janeiro: IBGE, 2004 a 2011.

PRADO, Eleutério F. S. Exame Crítico da Teoria da Financeirização. Disponível em: <http://eleuterioprado.files.wordpress.com/2013/09/exame-crc3adtico-da-teoria-dafinanceirizac3a7c3a3o1.pdf>. 2013. Acessado em: 30/02/2014.

. Lei de Marx: Pura Lógica? Lei Empírica? In. Marx e o marxismo 2013: Marx hoje, 130 anos depois. Niterói - $\quad$ RJ, 2013.2 Disponível em: <http://www.uff.br/niepmarxmarxismo/MM2013/Trabalhos/Amc444.pdf>, p. 1-18. Acessado em: 30/02/2014.

O marxismo pé-no-chão de David Harvey. In. CEMARX - VII COLÓQUIO INTERNACIONAL

MARX E 2012 . AnGels. Disponível em:
<http://www.ifch.unicamp.br/formulario_cemarx/selecao/2012/trabalhos/6248_Prado_Eleuterio .pdf>. Acessado em: 10/02/2014.

REVISTA CONJUNTURA DA CONSTRUÇÃO. Anos: V (n. 4), VI (n. 1), VIII (n. 1 e 3), X (n. 1 e 2), XI (n. 2) e XII (n. 1). São Paulo, vários anos.

REVISTA DO SISTEMA DE FINANCIAMENTO IMOBILIÁRIO. Ed. 32, 37 e 39. São Paulo: vários anos.

REVISTA NOTÍCIAS DA CONSTRUÇÃO. Ed. 93, 100, 105, 114 e 116. São Paulo, vários anos.

REVISTA O EMPREITEIRO. Ranking da Engenharia Brasileira, 500 grandes da construção. Ano LI, n. 521. São Paulo, julho 2013.

REVISTA RANKING ITC. As 100 maiores da construção. Ed. Especial, ano 1, n. 1. São Paulo, junho de 2013.

ROBUSTI, João Claudio. 2004-2007: Os anos da virada na construção. Revista "Conjuntura da Construção", São Paulo, ano VI, no 2, p. 12-13, junho de 2008.

ROCHA, Marilena. País atraiu R\$ 10 bi em investimentos. Jornal O Estado de São Paulo, São Paulo, 14/06/2013. Especial, Prêmio Top Imobiliário, H11, p. 61.

ROSDOLSKY, Roman. Gênese e Estrutura de O Capital de Karl Marx. Trad. César Benjamin. Rio de Janeiro: Eduerj: Contraponto, 2001. 
SECOVI. Balanço do Mercado Imobiliário em 2012. Disponível em: <http://www.secovi.com.br/files/Downloads/balaco-mercado-imobiliario-2012pdf.pdf>. Acesso em: 15/03/2014.

SILVA, Isabella F. B. R. Covered Bond: Alternativa de funding para o Mercado imobiliário brasileiro? (monografia), 2010.2 Disponível em: <http://www.bcb.gov.br/Nor/Denor/Paper_Covered_Bonds_Dez2010.pdf>. Acesso em: 12/01/2014.

SHIMBO, Lucia Z. Habitação social, Habitação de mercado: a confluência entre Estado, empresas construtoras e capital financeiro. $363 \mathrm{f}$. Tese - Escola de Engenharia de São Carlos, Universidade de São Paulo, 2010.

SMITH, Neil. A gentrificação generalizada: de uma anomalia local à "regeneração" urbana como estratégia urbana global. In: BIDOU-ZACHARIASEN, Catherine (Coord.). De Volta à Cidade: dos processos de gentrificação às políticas de "revitalização" dos centros urbanos. São Paulo: Annablume, 2006.

Gentrificação, a fronteira e a reestruturação do espaço urbano. GEOUSP - Espaço e Tempo, São Paulo, n²1, pp. 15-31, 2007.

TONE, Beatriz Bezerra. Notas sobre a valorização imobiliária em São Paulo na era do capital Fictício. 246 f. Dissertação (Mestrado em Habitat) - Faculdade de Arquitetura e Urbanismo, Universidade de São Paulo, São Paulo, 2010.

UQBAR. Anuário Securitização e Financiamento Imobiliário. Rio de Janeiro, 2013, p. 1-148.

VALOR ECONÔMICO. "Banco Morgan Stanley estréia em fundos imobiliários". Disponível em: <http://www.fundoimobiliario.com.br/noticia280510.htm>. Acessado em: 10/01/2011.

\begin{tabular}{|r|r|}
$\begin{array}{c}\text { Artigo submetido em } \\
\text { Artigo aceito em }\end{array}$ 24/04/2015 \\
\hline
\end{tabular}

